\title{
GREAT BRITAIN-continued.
}

\begin{tabular}{|c|c|c|}
\hline $\begin{array}{l}\text { Gray, Egerton. } \\
\text { Green, E. Collier. } \\
\text { Greene, A. } \\
\text { Greeves, R. A. } \\
\text { Griffith, A. D. } \\
\text { Griffith, A. H. } \\
\text { Grimsdale, H. } \\
\text { Gruber, R. } \\
\text { Gunning, C. J. H. } \\
\text { Hanson, Sgn. Capt.R. J. E. } \\
\text { Harries-Jonés, E. H. } \\
\text { Hawthorne, C. O. } \\
\text { Henderson, E. E. } \\
\text { Henderson, T. } \\
\text { Hepburn, Malcolm L. } \\
\text { Herbert, Lt.-Col. H. } \\
\text { Highet, H. C. } \\
\text { Hine, M. L. } \\
\text { Hird, R. B. } \\
\text { Hosford, Stroud. } \\
\text { James, R. R. } \\
\text { Jaques, R. } \\
\text { Joseph, H. M. } \\
\text { Juler, F. } \\
\text { Kiep, W. H. } \\
\text { Kirkpatrick, Lt.-Col. H. } \\
\text { Lang, Basil. } \\
\text { Lang, Wm. } \\
\text { Lawford, J. B. } \\
\text { Laws, W. G. }\end{array}$ & $\begin{array}{l}\text { Lawson, Sir Arnold. } \\
\text { Levy, A. H. } \\
\text { Lister, Sir W. T. } \\
\text { Lyle, H. W. } \\
\text { MacCallan, A. F. } \\
\text { MacCulloch, J. D. } \\
\text { Macdonald, P. } \\
\text { MacGillivray, Angus. } \\
\text { MacInnes, N. } \\
\text { Mackay, D. M. } \\
\text { MacKay, George. } \\
\text { MacLehose, N. M. } \\
\text { McMullen, W. H. } \\
\text { MacRae, A. } \\
\text { Mann, Ida. } \\
\text { Maxwell, E. M. } \\
\text { Mayou, Stephen. } \\
\text { Menzies, J. A. } \\
\text { Miller, G. V. } \\
\text { Moore, R. Foster. } \\
\text { Morgan, O. Gayer. } \\
\text { Neame, Humphrey. } \\
\text { Ormond, Arthur. } \\
\text { Parker, H. G. } \\
\text { Parsons, Sir J. Herbert. } \\
\text { Paton, Leslie. } \\
\text { Pickard, Ransom. } \\
\text { Pollock, W. B. I. } \\
\text { Pritchard, Eric L. } \\
\text { Quick, H. E. }\end{array}$ & $\begin{array}{l}\text { Ramsay, Maitland. } \\
\text { Ridley, N. C. } \\
\text { Roberts, B. H. St. Clair. } \\
\text { Ross, James A. } \\
\text { Rowan, J. } \\
\text { Russell, J. S. Risien } \\
\text { Rutledge, W. E. } \\
\text { Sinclair, A. H. H. } \\
\text { Smith, Lt.-Col. Hy. } \\
\text { Smith, Priestley. } \\
\text { Snowball, Thomas. } \\
\text { Souter, W. Clark. } \\
\text { Spicer, W. T. Holmes. } \\
\text { Stevenson, Edgar. } \\
\text { Thomson, Ernest. } \\
\text { Thomson, H. Wright. } \\
\text { Tomlinson, J. H.. } \\
\text { Traquair, H. M. } \\
\text { Tuckett, Ivor L. } \\
\text { Usher, C. H. } \\
\text { Valentine, J. A. } \\
\text { Walker, C. H. } \\
\text { Wallace, W. } \\
\text { Wharton, J. } \\
\text { White, Harry V. } \\
\text { Whitehead, A. L. } \\
\text { Whiting, M. H. } \\
\text { Williamson-Noble, F. A. } \\
\text { Wilson, David. } \\
\text { Wood, C. G. Russ. }\end{array}$ \\
\hline
\end{tabular}

Also an anonymous contribution, post-mark "Kingston Hill, Oct. 7," contained two postal orders. Mr. Leslie Paton will be glad if this contributor will communicate with him, as he gave no name or address.

\section{ABSTRACTS}

\section{I.-SYPHILIS}

(I) Fuchs, A. (Vienna).-Rare syphilitic affections of the eye. (Über einige seltene luetische Erkrankungen des Auges.) Zeitschr. f. Augenheilk., Bd. LVIII, SS. 315-345, May, 1926, and Bd. LIX, SS. 213-264, July, 1926.

(1) In two long and detailed papers Fuchs proposes to add to the ocular manifestations of specific infection two new clinical entities, and amplifies our pathological knowledge of a third.

1. Keratitis Linearis Migrans.

Igersheimer has classified the atypical forms of specific interstitial keratitis thus : 
(a) Annular keratitis.

(b) Keratitis with linear opacities running radially.

(c) Punctate keratitis.

(d) Phlyctenular keratitis.

(e) Gummatous keratitis.

To these Fuchs proposes to add a sixth-keratitis linearis migrans - a very rare condition, but one which presents a definite and typical clinical picture. Compare Collomb, "migratory superficial keratitis," Brit. 'jl. of Ophthal., Vol. VIII, p. 133).

He describes two cases of the condition in detail, and mentions a third which resembled them in appearance, but in which the characteristic progress of the disease was not verified since the patient was not kept under observation. The two cases were both females, aged 16 and 49 years. The syphilitic origin of the disease seems undoubted; both suggested hereditary infection, both had a positive Wassermann, both had anterior choroiditis, and the cornea of the other eye was affected with a typical interstitial keratitis.

The characteristic feature of the condition is a linear opacity starting in one quadrant of the cornea, and travelling slowly across it to the opposite quadrant. The opacity is situated deeply in the substance of the cornea, and it is intensified by a precipitate deposit on the posterior surface, which, however, shows no difference in level detectable by the slit-lamp. As the linear opacity travels across, these precipitates migrate in company with it. The band of opacity, which is seen by the slit-lamp to be made up of isolated white lines, stretches from limbus to limbus; it takes about six months to creep across the cornea in linear fashion, and in doing so different parts travel at different rates, so that its shape varies from time to time. As it progresses it leaves the cornea behind it clear, but in this area transient opaque spots sometimes appear, having a structure and position in the substance of the cornea similar to the line itself.

\section{Retino-choroiditis Diffusa Luetica.}

The histology of this somewhat rare condition, first described by Förster (1874), is dealt with in detail. The case from which the description is drawn was a man, aged 59 years, in whom the disease came on ten years after infection. The main symptom was a marked diminution of the visual fields, of which only a small central area for white remained. During life this seemed somewhat anomalous since the macula appeared ophthalmoscopically to be the part most severely affected; but pathological examination showed a minute region here which had remained normal. From his histological study, for details of which the original should be consulted, Fuchs concludes that the trouble began in the retina, 
not in the choroid. In the former the inner layers appeared to be affected first, and the outer layers only later, but in those areas showing advanced stages of the disease the outer layers were invariably affected most.

\section{Neuritis Papulosa.}

Fuchs defines a new clinical entity, which he proposes to call neuritis papulosa. It is a unilateral affection occurring in syphilitic subjects within the first two years after infection, wherein the anterior segment of the eye is apparently normal. It is characterized by an exuberant mass of exudate in relation to the papilla, accompanied by profuse and frequently repeated haemorrhages resulting in deep clouding of the vitreous, in which vision is diminished to the bare perception of hand movements. After a chronic course and under the influence of anti-syphilitic treatment, the condition eventually clears up to a very large extent, leaving permanent pathological residua, but at the same time a useful amount of vision.

He describes four cases of the condition, and from the literature he cites six which he considers fall into the same category, thus making ten in all. These six are : Liebreich (Atlas der Ophthalmoskopie, T.X, Abb. 1, 1863) described as Retinitis Syphilitica; Scheidemann (Arch. f. Ophthal., 1895, I) described as Gummatous newgrowth at the disc with "kolossale Perivaskulitis"; Gutmann (Centralbl.f. Augenheilk., 1907), and Mylius (Klin. Monatsbl. f. Augenheilk., 1913, I), similarly described; and Igerscheimer (Syphilis u. Auge, SS. 282, u. 441) two cases, the one described as Papillo-retinitis, and the other as Exudative Papillitis.

The primary focus is a circumscribed syphilitic infiltration of the papilla which results in the massive formation of exudate, which protrudes as an enormous grey, yellow, or white mass with sharplydefined edges into the vitreous, and terminates by anchoring itself in a patch of choroiditis somewhere on the retina. Elsewhere in the fundus there is an accompanying chorio-retinitis, leaving atrophic patches with pigmented deposits. There are many small white or yellow spots scattered over the retina, grouped especially under the retinal vessels; a constant feature is a star-shaped figure at the macula, differing from the appearance in albuminuric retinitis in that it is composed of grey rays, seen with difficulty, caused by folding of the retina; and sometimes there are regular stripes near the disc, caused by folding of the internal limiting membrane due to retinal oedema. There are numerous retinal haemorrhages, apart from which the vessels are little affected; and the vitreous is very clouded.

The disease comes on soon after infection (shortest case four months; longest, two years), and runs a very long chronic course. 
It finishes up with appearances resembling retinitis proliferans, where a narrow process of connective tissue stretches from the disc to a patch of atrophy towards the periphery : as this shrinks, however, detachment of the retina does not appear to occur, due presumably to its fixation peripherally in an atrophic patch.

The interference with vision is very great, and the fields show sector defects and scotomata. Under anti-syphilitic treatment the prognosis is not bad in spite of the severity of the disturbance : in two of the cases useful vision returned after many relapses, and after the vitreous had cleared up; in one normal vision returned; and one only resulted in blindness.

W. S. Duke-Elder.

\section{(2) LeRoux, H. (Caen).-A case of syphilitic tarsitis. (Sur un cas de Tarsite syphilitique.) Argh . d'Ophtal., September, 1926.}

(2) Syphilitic inflammation of the tarsus is sufficiently uncommon to justify the record of individual examples. The patient, a male, aged 50 years, had been under treatment for two months when he first came under LeRoux's care.

The right upper eyelid was dusky red, much enlarged, covering the upper half of the cornea so that the eye appeared to be half closed. The lid was of wooden consistency and could not be everted. The conjunctiva generally was congested, without excessive secretion. There was no pain, merely a little discomfort. In addition, there was, in the right temporal region, an area the size of "a two-franc piece" of ulceration of the skin, which had been diagnosed as epithelioma, and treated by X-rays. The right prae-auricular gland was enlarged. The patient denied venereal disease and stated that his general health had always been excellent. A Bordet-Wassermann test was strongly positive. Intravenous administration of novarsenobenzol once weekly was prescribed and Gibert's syrup given by mouth. After the sixth injection the tarsitis was completely cured, and the cutaneous ulceration wholly cicatrized.

Three types of syphilitic tarsitis are usually described :

(1) Marginal type, accompanied by ulceration, leading to deformity of the lid margin and partial or complete destruction of the lashes.

(2) A type characterized by circumscribed thickening, at the site of which deep ulceration soon develops.

(3) Diffuse swelling of the tarsus of one or more of the eyelids developing slowly and painlessly, the lid becoming very hard and resistant to palpation; eversion becomes impossible. If cut into the cartilage is found transformed into a lardaceous tissue with scanty blood supply. LeRoux's case belongs to this category. 
This manifestation of syphilis is most common in the tertiary stage. If treated early and vigorously it usually yields readily and leaves no deformity.

\section{J. B. LAWFORD.}

(3) Guy, W. H. (Pittsburg).-Interstitial keratitis in congenital syphilis. Jl. of Amer. Med. Assoc., November 6, 1926.

(3) Guy found 160 cases of interstitial keratitis among 2,536 syphilitic patients, or about 6 per cent: This incidence is much higher than that found by previous authors. Females accounted for 59 per cent., and males for 41 per cent., figures differing little from those given by Holmes Spicer and Cunningham. The earliest age of onset was one week and the latest 39 years. The age period of greatest incidence was from five to ten years, the same as that given by Holmes Spicer. In six of the 160 cases the attack was precipitated by trauma.

The Wassermann reaction in 144 cases was 2 to 4 plus; in six cases the reaction was 1 plus or entirely negative. In these latter cases the patients presented other well-marked signs of syphilis, or their parents or brothers and sisters did so. It would seem therefore that the Wassermann reaction is diagnostic but not pathognomonic.

As regards the pathology the author points out the similarity of the histological observations to those of late syphilis, in both of which there is a paucity of spirochaetes to be found, and in both of which we are dealing with a gummatous type of process.

The treatment is divided into local, general, and anti-syphilitic. The local treatment calls for no remark; the general treatment includes dental attention when indicated, and the patient's varying weight is carefully noted, which should increase; anti-syphilitic treatment includes : (a) iodides in all cases, on account of the histopathologic nature of interstitial keratitis resembling a gummatous condition; (b) arsenic compounds intravenously or intramuscularly; (c) mercuric chloride intra-muscularly.

In addition to clinical cure of patients an attempt is made to obtain a negative Wassermann reaction after each of three successive courses of treatment, to be followed by a year of observation, at three-month intervals. Treatment should be intermittent to avoid the development of arsenic- and mercury-fast strains of spirochaetes.

As regards the results of treatment the visual results were satisfactory. The second eye was involved during treatment in only three cases among 58 of the group that were unilateral when treatment was begun. Only four recurrences occurred.

A. F. MacCalda: 
(4) Ivanoff, G. (Geneva).-The serum diagnosis of ocular affections of syphilitic origin by the flocculation methods of Sachs-Georgi, Meinicke (M. T. R.) and Dreyer-Ward, as compared with the Bordet-Wassermann reaction. (Sérodiagnostic des affections oculaires d'origine syphilitique par les méthodes de floculation de Sachs-Georgi, de Meinicke (M. T. R.), et de Dreyer-Ward, comparées a la réaction de Bordet-Wassermann.) Rev. gén. d'Ophtal., November, 1924.

(4) The title of this article indicates, its scope. Since 1908 a great effort has been made to replace reactions depending on haemolysis by reactions depending on direct flocculation. "The physical modification which specific serum causes in colloidal suspensions is their precipitation, and a method has been sought to make this precipitation evident. This is a great advantage for the work is very much simplified thereby. The only important reagents are the suspected serum and the antigen, so that the animals necessary for the Bordet-Wassermann reaction are eliminated, expenses are reduced, and time is economized. Of the numerous flocculation procedures the three named in the title appear to be the most important and these have been systematically compared by Ivanoff with the Bordet-Wassermann reaction. The details are too technical for this journal : the conclusions seem to be the important thing so far as ophthalmic surgeons are concerned.

(1) The flocculation reactions undoubtedly reveal a disturbance in the physico-chemical composition of luetic sera and are therefore specific for syphilis.

(2) They appear to be less sensitive than the Wassermann reaction and do not possess the certainty of the latter.

(3) Their use runs fairly parallel with the method of Wassermann. Since they have advantages both as regards technique and cost they may be considered as procedures which are complementary in the serum diagnosis of syphilis.

(4) We may, then, make use of them in the serum diagnosis of ocular affections on condition that they are always compared with the Bordet-Wassermann reaction. The reactions should be carried out in well-equipped laboratories and in close relation to the clinic.

If, by the fourth conclusion, the author means that in every case in which these reactions are employed the Wassermann should be used as well, it is clear that expense will be increased rather than diminished. What is intended is, probably, that other workers should continue to compare the two types of reaction in order to obtain further evidence of their relative values.

ERnest ThOMSON. 
(5) Stokes, Dr. John H. (Philadelphia).-The Principles of Syphilo-therapy as applied to the eye. Arch. of Ophthal., May, 1927.

(5) Stokes's paper opens with a warning against regarding syphilis as a purely regional disease. He finds that specialists in fields other than that of venereal disease "make comparatively ineffective syphilotherapists to-day, for their point of view is apt to be local and restricted ... . " also "they think symptomatically rather than systemically, palliatively rather than curatively." The ophthalmologist in particular has seen the misapplications and deficiencies rather than the good effects of modern treatment, and so does not appreciate what really can be accomplished for the patient with ocular syphilis.

There are two basic principles in modern syphilotherapy: (1) treatment should not be begun with shock-producing drugs such as arsphenamine, until the entire condition of the patient with reference to syphilis has been fully evaluated by a complete examination; (2) syphilis of a special structure should be treated as part of the general disease. Treatment with arsphenamine does three things : (1) it produces a flare-up of the disease (Herxheimer reaction) when first given, which may be damaging or fatal if unrecognized involvement of a vital structure exists; (2) it produces hypersensibility and a fulminating relapse if stopped too soon; (3) it produces healing and fibrosis so rapidly that there is little time for functional adaptation in the structures most seriously involved. In order to avoid (1) - a bad Herxheimer reaction-patients with severe and acute lesions should have a preparatory course with slower-acting drugs and graded arsphenamine dosage. In order to avoid (2), it is essential to continue the arsphenamine for a period sufficiently long to destroy the spirochaetes and not leave groups of them ready to proliferate, as soon as the drug has disappeared from the blood. The consequences of (3)-rapid fibrosis-were first observed in the liver, and it is probable that a similar process is responsible for the rapid development of blindness in some cases of tabes, treated by arsphenamine. It is therefore necessary in these cases also to have a long preparatory period with slow-acting, non-fibrosing drugs, producing "a proper crescendo between the pianissimo beginnings that prevent shock and fibrosis and the fortissimo ending that produces lasting results to the great benefit of the patient." With regard to the effect of various drugs : arsphenamine, which attacks the spirochaete direct, is responsible for therapeutic shock ; mercury which acts by stimulation of cellular resistance, and iodide which causes lysis of granulomata, do not produce flare-ups. Bismuth lies midway between mercury and arsphenamine. It will thus be seen how a proper sequence in the use of drugs combined with a 
proper selection of vehicle, mode of administration and dosage, can secure results unobtainable by rule-of-thumb methods.

The author is not greatly impressed by local treatment, e.g., intraspinal injections, and finds that it is being slowly superseded as general treatment becomes more effective. Factors other than the primary cause must also be considered, and means should be taken to eradicate focal infections, secure rest and so on. Of the arsphenamines, 606 is the most effective though also the most difficult to use. It should, however, be employed in ocular syphilis "when a minute and difficultly accessible lesion may be responsible for serious damage in a short time." Under-dosage with an ineffective arsphenamine (neoarsphenamine) at irregular and overlong intervals for an insufficient series of injections forms the explanation of many disappointments and failures. Mercury in ocular syphilis should be administered daily by intramuscular injection or by inunction and not by the mouth. In a rapidly advancing process, where arsphenamine cannot be used at the outset, its combination with a soluble mercurial (the succinimide or bichloride) given intramuscularly may perform veritable miracles. The points about iodide are as follow :

Experimental work tends to show that small doses are more effective in elevating general resistance to syphilis. Clinically, however, it is found that a high concentration in the blood is required to produce penetration of the drug into parts of the body which are difficult of access. The author seldom prescribes less than 15 grains of potassium iodide t.i.d. and usually gives 50 grains t.i.d., not infrequently 100 , and at times even 250 or 500 grains t.i.d. Intravenous administration of sodium iodide is useful in neurosyphilis. Interstitial keratitis calls for intensive treatment by the simultaneous use of arsphenamine intravenously, mercury succinimide intramuscularly and liberal doses of potassium iodide by the mouth, followed up by bismuth and arsphenamine with inunctions and iodide between courses. By such means the disease, if seen early, can be limited to one eye in all but a few cases.

\section{F. A. Williamson-Noble.}

(6) Fuchs, Ernest. - Ocular manifestations in cerebral syphilis, tabes, and general paralysis. (Manifestaciones oculares de la tabes y la paralysis general.) Arch. de Oftal. de Buenos Aires, June, 1927.

(6) Professor Fuchs has given a series of ten lectures in Buenos Aires, of which nine transcripts are being printed. The first résumé deals with syphilis and parasyphilis and was read to the Argentine Medical Association.

While the correlation of syphilitic signs and symptoms has 
been proceeding during the past centuries, and earlier diagnosis has been made possible of recent years, the manifestations !ave changed from dermal to visceral and neural. The contrasting aetiology of dermal and neural syphilis has been diversely explained: two types of spirochaetes have been postulated, the dermal attacking primitive peoples, the neural the more civilized. The greater prevalence of parasyphilis in towns is explained in two ways :

(1) The more intelligent are more prone to neural involvement.

(i) Early treatment before the exanthem predisposes to parasyphilis. The skin rash is believed to produce antibodies protecting the nervous tissues. Is the safeguarding of the race a menace to the individual?

The spirochaete in cerebral syphilis is meningeal and perivascular, "mesodermal," and is therefore amenable to circulatory therapy. In parasyphilis it is in the actual nervous "ectodermal" tissue, and drugs administered by mesodermal routes cannot reach it. Meningeal spirochaetosis may occur in the first few weeks of the infection with pain in the head and hyperaemia of the disc, vision being unaffected. Prostitutes and tertiary syphilitics are more liable to cerebral lues than to parasyphilis; the one condition never leads to the other.

The pseudo-Argyll Robertson pupil, generally unilateral, occurs in complete oculomotor paralysis, and is due to the naturally more facile response to accomodo-convergence, the attempt at which, though impossible, produces reciprocal sympathetic inhibition and dilator relaxation.

Tabetic muscular paralyses are nuclear and their transient nature suggests the likelihood that they are due to syphilitic toxin rather than to the spirochaete. The levator palpebrae is most frequently affected. A tabetic can temporarily compensate for his ptosis or squint by voluntary effort; he does not suffer extremely from the discomfort or vertigo consequent on diplopia. Tabetic ptosis varies with conjugate deviation, the palpebral aperture widening when the patient looks to the opposite side and narrowing with the glance to the same side as the lesion, by nuclear spread of the impulse, active or inhibitory, to the internal rectus.

A paracentral scotoma appears sometimes (5 per cent.), but the concentric contraction commences and becomes extreme to the side of this, so that the remnant of field bordering it is a mere bridge over a sector defect. The chiasma may rarely be attacked by syphilitic toxin, as also by that of disseminated sclerosis, producing bitemporal hemianopsia. The affinity of this toxin for the nerve bundle linking the superior corpus quadrigeminum with the third nucleus explains the Argyll Robertson pupil. The spirochaete could not do such slight and selective damage. 
Antiluetic therapy cannot ameliorate the degenerative optic atrophy; the author is not convinced by the contention of others that treatment makes it worse. Against parasyphilis it is ineffectual, being prevented access to the nerve tissue by the neuroglia. Wagner's febrile treatment, for which the malarial parasite is now employed as its effects are controllable, is based on the assumption that spirochaetes cannot survive 40 to 41 degrees centigrade.

D. Stenhouse Stewart.

\section{II.-MISCELLANEOUS}

(1) Discussion on birth injuries of the eye. Trans. Ophthal. Soc., U.K., 1926.

(1) Comyns Berkeley, in the opening paper, said that he had hitherto believed that birth injuries to the eye were rare, though Lequeux states that in eyes examined 24 hours after birth, disturbance of some sort is present in 25 per cent. of cases, in this order: paralysis of muscles, corneal lesions, retinal haemorrhages. Paul found retinal haemorrhages in 20 per cent. of normal births, in 40 per cent. of premature births, and cases of non-instrumental, protracted labour, and in 50 per cent. of cases of contracted pelvis. Injuries may be prevented under certain conditions by anticipation of difficult labour before it occurs, and by care and intelligence in terminating the labour. Laceration of the eyelids, contraction of the palpebral fissure, laceration of the lacrymal duct, exophthalmos, injury to the external rectus, luxation and avulsion of the eyeball, crushing of the eyeball, luxation of the lens and corneal injuries may be due to pressure from a blade of a forceps. Fracture of the skull or laceration of the tentorium may produce an intracranial haemorrhage, followed by ptosis of the upper eyelid, paralysis of the external rectus, or a combined paralysis of the sixth and seventh nerves. Fracture of the skull may also involve an injury to the optic and other nerves in their course through foramina or fissures to the eyeball. The great congestion of the head and face which is sometimes present at the end of a prolonged, but otherwise, normal labour, or when the umbilical cord is coiled tightly round the neck, may result in oedema of the lids, retrobulbar haematoma leading to exophthalmos, haemorrhage into the anterior chamber, or retinal haemorrhage. In repeated vaginal examinations the cornea may be injured, and most cases of avulsion of the eyeball are due to gross carelessness in such circumstances. Such injuries, however, with the exception of retinal haemorrhages, appear to those engaged in midwifery to be rare. This is supported by the figures of de Wecker, Truc, and Wolff. It is probable that as 
difficult labour due to contracted pelvis is now being anticipated in so many cases, these eye lesions are becoming rarer.

(2) Ernest Thomson gave the following list of birth injuries :Dislocation, extrusion, avulsion, or evulsion; corneal injuries, fractures and dents of the skull in the orbital region, including the lacrymal bones. The attachments of the eye may be severed by fractured bone, and tears of the skin and conjunctiva and general bruising may occur. Haemorrhage may occur into the conjunctiva, subcutaneous tissues, or orbit. In the latter case, if profuse, it produces exophthalmos. Intracranial haemorrhage (also discussed by Buchanan). Paralysis of the third, sixth, seventh, and sympathetic nerves. The injuries most likely to escape notice at the time of birth are haemorrhage within the eyeball or within the cranial cavity. Retinal haemorrhages occur with comparative frequency in normal, and even in premature labour. Cataract may occur as a birth injury. It is incomplete, unilateral, and lamellar, and may be sector-shaped. Nystagmus for which no definite cause can be assigned is often seen by those who deal with large numbers of school children and may be due to injury at birth. Fundus changes may be absent. Right-sided nystagmus has been produced experimentally by injury to the left cerebral peduncle (Mangold and Löwenstein) and unilateral nystagmus would appear to depend on injury to some fibres in the peduncle. Squint may be due to birth injury, especially when the external rectus seems weak. Sympathetic paralysis as a result of birth injury has been recorded. It is possible that certain conditions, not hitherto associated with birth injury, may sometimes conceivably come into that category. The most important is myopia, especially congenital unilateral myopia. There are also to be considered retinal detachment, hole at the macula, choroido-retinal atrophy at the macula, angeoid streaks in the retina, buphthalmos, unilateral aniridia, posterior lenticonus, oxycephaly, and anterior staphyloma.

(3) Leslie Buchanan said that he intended to limit his remarks largely to injuries affecting the eye indirectly rather than directly. In 32 per cent. of all haemorrhages there were gross exudations inside the cranium, and in 20 per cent. tears of the tentorium cerebri or cerebelli. Apart from congenital idiocy and large paralyses and contractures, other sequelae of intracranial haemorrhage may lead the parent to consult an ophthalmic surgeon, such complaints being common as "not taking notice," "the eyes do not keep steady," etc. The history of the labour is not so important, in such cases, as the history of the child a few minutes after birth, because damage may occur in a child born easily and naturally, and the signs of the damage may be of brief duration, such as a few twitchings of limbs. On' the other hand, intense asphyxia after birth is important as a possible cause of 
haemorrhages. Cuts and bruises of the head, haemorrhagic effusion under the scalp, and undue mobility of bones may indicate damage to the scalp, with which intracranial or intraorbital damage is often associated. The use of forceps indicates a considerable degree of violence and torsion of the head, while in cases of after-coming head the tendency to damage inside the head is possibly greater than otherwise. Illustrative cases were then quoted.

(4) Frank Juler said that he had examined the fundi of 158 newborn infants at Queen Charlotte's Hospital during the first eight days after birth, and found retinal haemorrhage in 14. Later, appreciating the rapidity with which such haemorrhages may absorb, he examined 58 in the first 24 hours, finding haemorrhages in nine. The appearances are as follow: haemorrhage usually abundant, spread out in thinnish sheets in the nerve fibre layer, and confined to the posterior pole. Sometimes large dark clots are present. The thin sheets and small flecks usually disappear within a week. "The frequency of the haemorrhage and persistence of the dense circular haemorrhages at the macula suggest that we have here a cause of defective macular vision of various types, in which ophthalmoscopic evidence of anatomical defect might range from quite obvious changes, such as choroido-retinal atrophy to conditions in which there is no visible lesion."

The cause of the haemorrhage is most likely the excessive pressure to which the head is subjected in its passage through the pelvis, leading to congestion of the veins which drain the cerebral sinuses.

"Abnormalities of the labour which tend to increase the cranial pressure appear to exercise little effect on the incidence of retinal haemorrhage."

(5) Arthur W. Ormond said that certain cases suggest that instrumental birth and the difficulties of prolonged labour may be a cause in producing $(a)$ a marked degree of anisometropia, $(b)$ a condition where in one eye the amblyopia is so profound that it is not likely to be the result of any amblyopia ex anopsia as in ordinary squint, (c) definite scarring of the cornea, with splits of Descemet's membrane, (d) certain cases of congenital nystagmus, $(e)$ anomalous conditions of the extra-ocular muscles producing paralytic squints in children, $(f)$ atrophic patches and pigmentary areas, the result of haemorrhages.

(6) J. Rowan mentioned three cases with bands of opacity in the cornea, marked astigmatism, and very bad vision (even with correction) in one eye, the other eye having full vision.

(7) E. Treacher Collins quoted cases giving definite evidence of myopia as a sequel to birth injury.

(8) A. J. Ballantyne said that there was general agreement that birth injuries to the eyes are less frequent in hospital practice than they used to be. He then described a form of birth injury in which 
there is a permanent detachment of part of Descemet's membrane from the cornea.

(9) T. H. Whittington said that injuries could occur in rapid labour without instrumental interference.

G. G. Penman.

(2) Beaucamp, C. (Hamburg).- The treatment of ocular tuberculosis by the internal administration of the partial antigen of Deycke. (Über die innerliche Behandlung der Augentuberculose mit Partialantigenen von Deycke.) Zeitschr. f. Augenheilk., Bd. LIX. SS. 290-j00, July, 1926.

(2) "The Partial Antigen of Deycke" (Zeitschr. f. Tuberkul., XL, 3; Münch. med. Woch., 1924, 17; Die Tuberkul., 1925, 2), which is administered orally, has been used by Beaucamp in a series of 50 cases of tuberculosis of the eye, embracing lesions of the orbit, the cornea, the iris, the choroid, and the retina. The general conclusion he comes to is that the new medicament is a valuable therapeutic agent. Its main advantages are the ease and convenience of its administration by the oral route, and the absence of general reaction as evidenced by a rise of temperature. The antigen can be used subcutaneously, but it would seem to be effective when given by the mouth when other methods fail. Tuberculous iritis and tuberculous kerato-conjunctivitis have shown the most satisfactory response in Beaucamp's hands.

\section{W. S. DUKL-ELDER.}

\section{(3) Cox.-Headache of nasal origin. New York State Jl. of Med., April 10, 1925.}

(3) Cox's paper is of interest to ophthalmologists in as far as a differential diagnosis between headaches of ocular and nasal origin is concerned. The author points out that the frequency of headache as a symptom of nasal abnormalities is due to the common nerve supply, by the trigeminus, of the nose and accessory sinuses, and of the dura mater. He subdivides the noninflummatory affections into :

(1) Pure pressure cases due to terminal nerve pressure resulting from deflected septum, hypertrophied turbinates or adhesions between the two. The resultant pain is mainly localized to the nasal bridge, orbit and temple, is worse in the mornings, and the sufferer is usually of a type possessing a low reserve of nervous endurance. The author records several cures of headache of years' duration by the correction of such abnormalities.

(2) The so-called vacuum frontal headache,' which is described as a low-grade constant pain, worse in the mornings, and aggravated by near work, unrelieved by glasses. Ewing's sign, e.g., tenderness on pressure over the upper inner angle of the orbit, is frequently present. The condition is produced by a 
narrowing of the frontal sinus outlet into the middle meatus by means of an enlargement of the bulla in front, or processus uncinatus behind, or merely by a deflection of the septum.

(3) The nasal (Meckel's) ganglion neuroses. Slade, of St. Louis, has described the following syndrome occurring in such cases. The pain is generally felt at the root of the nose, in the orbit and upper jaw and may extend down the shoulder on the affected side, as far as the fingers. There may also be present, salivation, a perverted sense of taste (metallic) and scotoma scintillans. The immediate temporary relief of pain following the direct application of cocaine to the ganglion, serves to differentiate between a neurosis and an irritation, the result of sphenoiditis.

In dealing with the inflammatory nasal conditions the author notes the greater ease in arriving at the under-lying cause of the accompanying headache. An examination of the nerves is usually more illuminating, while swelling of the eyelids, exophthalmos, and paresis of various ocular muscles assist in the diagnosis.

In conclusion the author refers to the uncertainty of the locality of pain due to an affection of any one of the nasal sinuses but notes several suggestive areas, e.g., the occiput in sphenoidal, the cheek and upper teeth in maxillary, and the course of the supraorbital nerve, in frontal disease.

E. Maxwell.

\section{BOOK NOTICES}

Applied Refraction. By Homer Smith. Pp. 130. Edinburgh: E. and S. Livingstone. 1927. Price, 15s.

The keynote of this book is found in the introduction: "The personal equation governs the selection of lenses and the psychic element dominates the scientific." The author insists on the importance of repose of the body and mind, both in the patient and in the surgeon, and insists that tact and perseverance are essential to good work. He says "the refractionist is born and not made."

He illustrates a special test chart which can be used under varying degrees of illumination, also for testing the light-sense and for selecting the tint required by hypersensitive eyes. It is ar ideal instrument, but of course a rather expensive luxury. $\mathrm{He}$ makes no mention whatever of retinoscopy as an aid to sighttesting, and although he uses the ophthalmometer he seems to rely almost entirely on subjective testing. This he combines with an exaggerated employment of cycloplegics. He says any patient who has any evidence of eye strain, be she seven or seventy, must be examined under full cycloplegia. Notwithstanding the most 